\title{
PRODUTIVIDADE E QUALIDADE DA BRACHIARIA IRRIGADA NO
} OUTONO/INVERNO

Doi:http://dx.doi.org/10.1590/1809-4430-Eng.Agric.v36n3p469-481/2016

\section{GEFFSON DE F. DANTAS ${ }^{1}$, ROGÉRIO T. DE FARIA ${ }^{2}$, GILMAR O. SANTOS ${ }^{3}$, ALEXANDRE B. DALRI ${ }^{4}$, LUIZ F. PALARETTI ${ }^{5}$}

\begin{abstract}
RESUMO: Um dos fatores que determinam os baixos índices zootécnicos na pecuária brasileira é a estacionalidade da produção das plantas forrageiras tropicais. A irrigação pode proporcionar aumento e estabilização da produtividade durante o outono e o inverno. Objetivou-se pelo presente estudo avaliar: a) a produtividade de massa seca e qualidade de forragem de Brachiaria brizantha, em função de lâminas de irrigação, no período do outono e do inverno; b) a umidade do solo e a temperatura do ar a fim de determinar seus efeitos na produtividade de forragem. O experimento foi conduzido na Fazenda Experimental da FCAV-Unesp, em Jaboticabal-SP. Utilizou-se de um sistema de aspersão em linha para estabelecer tratamentos com cinco lâminas de irrigação correspondentes a frações da evapotranspiração de referência $\left(\mathrm{L}_{1}=0,18 ; \mathrm{L}_{2}=0,52 ; \mathrm{L}_{3}=1,00 ; \mathrm{L}_{4}=\right.$ 1,45 e $\mathrm{L}_{5}=1,67$ ), em duas estações do ano: outono e inverno. A produtividade de forragem foi mais elevada no outono, e a resposta de produtividade à lâmina de água foi ajustada por uma função quadrática, atingindo produtividades máximas com lâminas de 267 e $269 \mathrm{~mm}$ para o outono e o inverno, respectivamente. Alto valor nutritivo da forragem foi obtido em ambas as estações do ano, com incrementos nos teores de proteína bruta com acréscimo da lâmina de irrigação somente no outono. As lâminas de água não afetaram os teores de fibra detergente neutro da forragem.
\end{abstract}

PALAVRAS-CHAVE: Brachiaria brizantha, forragem, irrigação.

\section{HERBAGE YIELD AND QUALITY OF IRRIGATED BRACHIARIA IN AUTUMN AND WINTER}

\begin{abstract}
One of the reasons of low performance of the Brazilian livestock industry include the seasonal growth of tropical pasture grasses. Irrigated grasslands may have higher and most stable rates of yield during autumn and winter seasons. Therefore, we aimed at evaluating: a) Brachiaria brizantha dry matter yield and forage quality as a function of different water depths during the autumn and winter, and b) soil moisture and air temperature effects on forage yield. The experiment was carried out at the Experimental Farm of the University of São Paulo State (FCAV - UNESP), campus in Jaboticabal - SP, Brazil. We used a line-source sprinkler system to provide five levels of irrigation $\left(\mathrm{L}_{1}=0.18, \mathrm{~L}_{2}=0.52, \mathrm{~L}_{3}=1.00, \mathrm{~L}_{4}=1.45\right.$, and $\left.\mathrm{L}_{5}=1.67\right)$. These water depths corresponded to fractions of reference evapotranspiration in both autumn and winter. Forage yield was higher in autumn and water depth responses were fitted by a quadratic function, reaching maximum values at 267 and $269 \mathrm{~mm}$ during autumn and winter, respectively. During the autumn, we observed a highly nutritive forage with crude protein increment by increasing water depths. However, water application had no effect on neutral detergent fiber content.
\end{abstract}

KEY WORDS: Brachiaria brizantha, forage, irrigation.

\footnotetext{
${ }^{1}$ Licenciado em Ciências Agrárias, Mestre em Agronomia (Ciência do Solo), Departamento de En genharia Rural, FCAVUNESP/Jaboticabal - SP, geffson@hotmail.com

${ }^{2}$ Eng $^{\mathbf{o}}$ A grônomo, Prof. Doutor, Departamento de Engenharia Rural, FCAV-UNESP/Jaboticabal - SP, rogeriofaria@ fcav.unesp.br

${ }^{3}$ Eng $^{\circ}$ Ambiental, Prof. Doutor, Departamento de Engenharia Ambiental, Universid ade de Rio Verde/Rio Verde - GO, gilmar@unirv.edu.br

${ }^{4}$ Eng $^{\circ}$ A grícola, Prof. Doutor, Departamento de Engenharia Rural, FCAV-UNESP/Jaboticabal - SP, dalri@ fcav.unesp.br

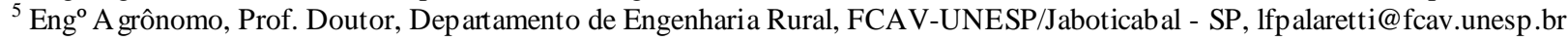
Recebido pelo Conselho Editorial em: 18/05/2015

Aprovado pelo Conselho Editorial em: 22/02/2016
} 


\section{INTRODUÇÃO}

O Brasil, por ser um dos maiores produtores e exportadores de carne do mundo, ainda apresenta baixo nível tecnológico em sua produção (MAPA, 2014). De acordo com o último Censo Agropecuário Brasileiro, realizado em 2006 (IBGE, 2007), o País possui grande quantidade de terras ocupadas com pastagem, aproximadamente 160 milhões de hectares, porém a maior parte está degradada, e a produção de gado no País é feita com a taxa de 1,3 animal UA ha ${ }^{-1}$. A pecuária brasileira tem sido demandada a estabelecer sistemas de produção que sejam capazes de produzir, com eficiência, carne de boa qualidade e baixo preço (SILVA et al., 2009).

As pastagens são a maneira mais prática e econômica para a alimentação de bovinos, garantindo baixos custos de produção (ALENCAR, 2010; DIAS-FILHO, 2014). Há necessidade de intensificar os sistemas de produção de forragem otimizando os fatores relevantes de seu manejo, para obter maiores incrementos na produtividade de biomassa e na qualidade produzida. Um dos fatores que determinam os baixos índices zootécnicos é a estacionalidade da produção das plantas forrageiras tropicais nos períodos mais secos do ano (VITOR et al., 2009). O efeito da sazonalidade da produção de pastagens no Brasil é determinado, basicamente, pela diminuição da radiação solar, da temperatura e da precipitação, ocorrendo, assim, desuniformidade na distribuição de oferta de forragem ao longo do ano, com menor produtividade no outono/inverno e abundante na primavera/verão (DRUMOND \& AGUIAR, 2005). As temperaturas ótimas para pastagens subtropicais situam-se entre a faixa de 25 a $35^{\circ} \mathrm{C}$, enquanto temperaturas entre 10 e $15^{\circ} \mathrm{C}$ comprometem a produtividade e podem limitar em até $36 \%$ a produtividade de forragem (TONATO, 2003; RODRIGUES, 2004).

Forrageiras do tipo Brachiaria brizantha têm sido consideradas adaptadas para as épocas mais secas do ano, por apresentar boa produtividade de forragem, baixo acúmulo de colmos e boa retenção de folhas verdes. Porém, seu cultivo exige técnicas de manejo para que se tenham níveis aceitáveis de desempenho dos animais no período seco do ano (SILVA et al., 2009).

$\mathrm{O}$ valor nutritivo da forragem está associado aos teores de proteína bruta (PB) e fibra em detergente neutro (FDN), que são influenciados pela quantidade de nitrogênio aplicado e pela estacionalidade (VITOR et al., 2009). Em períodos de menor precipitação, a baixa disponibilidade hídrica no solo causa baixa eficiência da adubação nitrogenada, resultando em menor produção e qualidade da forragem (TEIXEIRA et al., 2011; SANTOS et al., 2009). A estacionalidade, por sua vez, determina a idade do pasto no momento de sua utilização e também sua produtividade; a composição folha/haste, por sua vez, interfere no valor nutritivo da forragem.

Dentre as possibilidades para a melhoria do manejo de pastagem na pecuária brasileira, a irrigação constitui uma tecnologia que proporciona incrementos e estabilização de produtividade, uma vez que pode suprir a demanda hídrica durante a época seca do ano e suplementá-la na época chuvosa (ALENCAR et al., 2009a; LOPES et al., 2014).

$\mathrm{O}$ alto custo da técnica de irrigação, a escassez de água e a falta de informação sobre as necessidades hídricas das pastagens constituem as mais importantes limitações para adoção dessa técnica no manejo das pastagens. A falta de critérios técnicos na irrigação de pastagens resulta em aplicações de água em excesso e pode causar prejuízos ao ambiente, alto consumo de energia elétrica, lixiviação de nutrientes, compactação do solo, diminuição da produtividade e vida útil da pastagem (ALENCAR et al., 2009b). Portanto, pesquisas visando a obter informações sobre o uso racional da água são de fundamental importância para a viabilização econômica e ambiental da forragicultura irrigada.

A região de Jaboticabal-SP, apresenta temperatura adequada para o desenvolvimento de plantas forrageiras do tipo braquiária, porém o período do outono/inverno tem como característica ser relativamente seco, com $56 \mathrm{~mm}$ de deficiência hídrica concentrada no inverno (ROLIM et al., 2007; UNESP, 2014). Essa característica climática condiciona baixa distribuição da oferta de forragem nesse período, carecendo da irrigação para suprir a demanda hídrica da cultura e, então, 
proporcionar acréscimos de produtividade durante períodos de temperaturas acima do nível térmico crítico.

A fim de testar a hipótese de que o manejo da irrigação com diferentes lâminas, no período do outono/inverno, pode aumentar a produtividade e a qualidade de forrageiras, o presente estudo objetivou avaliar: a) produtividade de massa seca e qualidade de forragem de Brachiaria brizantha, cv Marandu, em função de lâminas de irrigação no período do outono e do inverno; b) monitorar a umidade do solo e a temperatura do ar a fim de determinar seus efeitos na produtividade de forragem.

\section{MATERIAL E MÉTODOS}

O experimento foi conduzido na Fazenda Experimental da FCAV-UNESP, em JaboticabalSP, com latitude de $21^{\circ} 14^{\prime} 05^{\prime \prime S}$, longitude $48^{\circ} 17^{\prime} 09^{\prime} \mathrm{O}$ e altitude de $615 \mathrm{~m}$. O clima da região, segundo a classificação de Thornthwaite, é do tipo B1rB'4a', relativamente seco no inverno, com chuvas no verão, apresentando temperatura média anual de $22,2^{\circ} \mathrm{C}$ e precipitação de $1.425 \mathrm{~mm}$. No outono e no inverno, as temperaturas médias são de 20,3 e $20,6{ }^{\circ} \mathrm{C}$, e a precipitação de 51,6 e 39,3 $\mathrm{mm}$, respectivamente (UNESP, 2014).

O solo da área experimental é classificado como Latossolo Vermelho eutroférrico típico, com textura muito argilosa (ANDRIOLI \& CENTURION, 1999), com as características químicas, físicas e hídricas apresentadas na Tabela 1.

TABELA 1. Características química, física e hídricas do Latossolo Vermelho eutroférrico da área experimental, em 2014. Physico-chemical and hydric properties of eutroferric Red-Latosol (Oxisol) in the experimental area, in 2014.

Características químicas

\begin{tabular}{|c|c|c|c|c|c|c|c|c|c|c|}
\hline $\begin{array}{c}\text { Prof. } \\
\mathrm{cm}\end{array}$ & $\begin{array}{c}\mathrm{pH} \\
\left(\mathrm{CaCl}_{2}\right)\end{array}$ & $\begin{array}{c}\text { M.O } \\
\mathrm{mg} \mathrm{dm}^{-3}\end{array}$ & $\begin{array}{c}\mathrm{P} \\
\mathrm{mg} \mathrm{dm^{-3 }}\end{array}$ & $\mathrm{K}$ & $\mathrm{Ca}$ & $\begin{array}{l}\mathrm{Mg} \\
---\mathrm{mmc}\end{array}$ & $\begin{array}{r}\mathrm{H}+\mathrm{Al} \\
\mathrm{lc} \mathrm{d} \mathrm{m}^{-3}\end{array}$ & SB & $\mathrm{T}$ & $\begin{array}{l}\mathrm{V} \\
\%\end{array}$ \\
\hline $0-20$ & 5,4 & 26,0 & 68,0 & 5,9 & 31,5 & 16,5 & 32,5 & 53,9 & 86,4 & 62,0 \\
\hline
\end{tabular}

Características físicas e hídricas

\begin{tabular}{|c|c|c|c|c|c|c|c|c|}
\hline $\begin{array}{c}\text { Prof. } \\
\mathrm{cm}\end{array}$ & Өs & $\begin{array}{c}\Theta \mathrm{cc} \\
\mathrm{cm}^{3} \mathrm{~cm}^{-3}\end{array}$ & Өpmp & $\begin{array}{c}\mathrm{ds} \\
\mathrm{Mg} \mathrm{m}^{-3}\end{array}$ & Areia & $\begin{array}{l}\text { Argila } \\
-\mathrm{g} \mathrm{kg}^{-1}\end{array}$ & Silte & Textura \\
\hline $0-20$ & 0,472 & 0,398 & 0,266 & 1,45 & 221 & 566 & 213 & Argilosa \\
\hline $20-40$ & 0,442 & 0,404 & 0,293 & 1,49 & 208 & 592 & 200 & Argilosa \\
\hline $40-100$ & 0,486 & 0,385 & 0,264 & 1,34 & 209 & 598 & 193 & Argilosa \\
\hline
\end{tabular}

*Prof. = profundidade; M.O = matéria orgânica; ds = densidade do solo; Os, Occ e Opmp refere-se à umidade na saturação, capacidade de campo e ponto de murcha permanente, respectivamente.

Os tratamentos constituíram-se de cinco lâminas de irrigação em duas estações do ano, outono e inverno, distribuídos em delineamento bifatorial, com parcelas subdivididas, em blocos ao acaso, com quatro repetições (Figura 1). As lâminas de irrigação foram alocadas na parcela, e as estações do ano, na subparcela.

As lâminas de irrigação foram calculadas em função de frações da evapotranspiração de referência $\left(\mathrm{ET}_{0}\right)$, correspondentes a $\mathrm{L}_{1}=0,18 ; \mathrm{L}_{2}=0,52 ; \mathrm{L}_{3}=1,00 ; \mathrm{L}_{4}=1,45$ e $\mathrm{L}_{5}=1,67$ (Figura 2), aplicadas com frequências de uma a duas vezes por semana. A distribuição gradual da precipitação foi obtida por um sistema de aspersão em linha, com aspersores Senninger (Modelo 3023-2 com duplo bocal de $8 \times 5 \mathrm{~mm}$ ), operados com pressão de $300 \mathrm{kPa}$, no espaçamento, $6 \mathrm{~m}$ entre aspersores na linha. $\mathrm{O}$ sistema de irrigação apresentou coeficiente de uniformidade de Christiansen (CUC) e coeficiente de uniformidade de distribuição de água (CUD) de cerca de 89 e 83\%, respectivamente. 


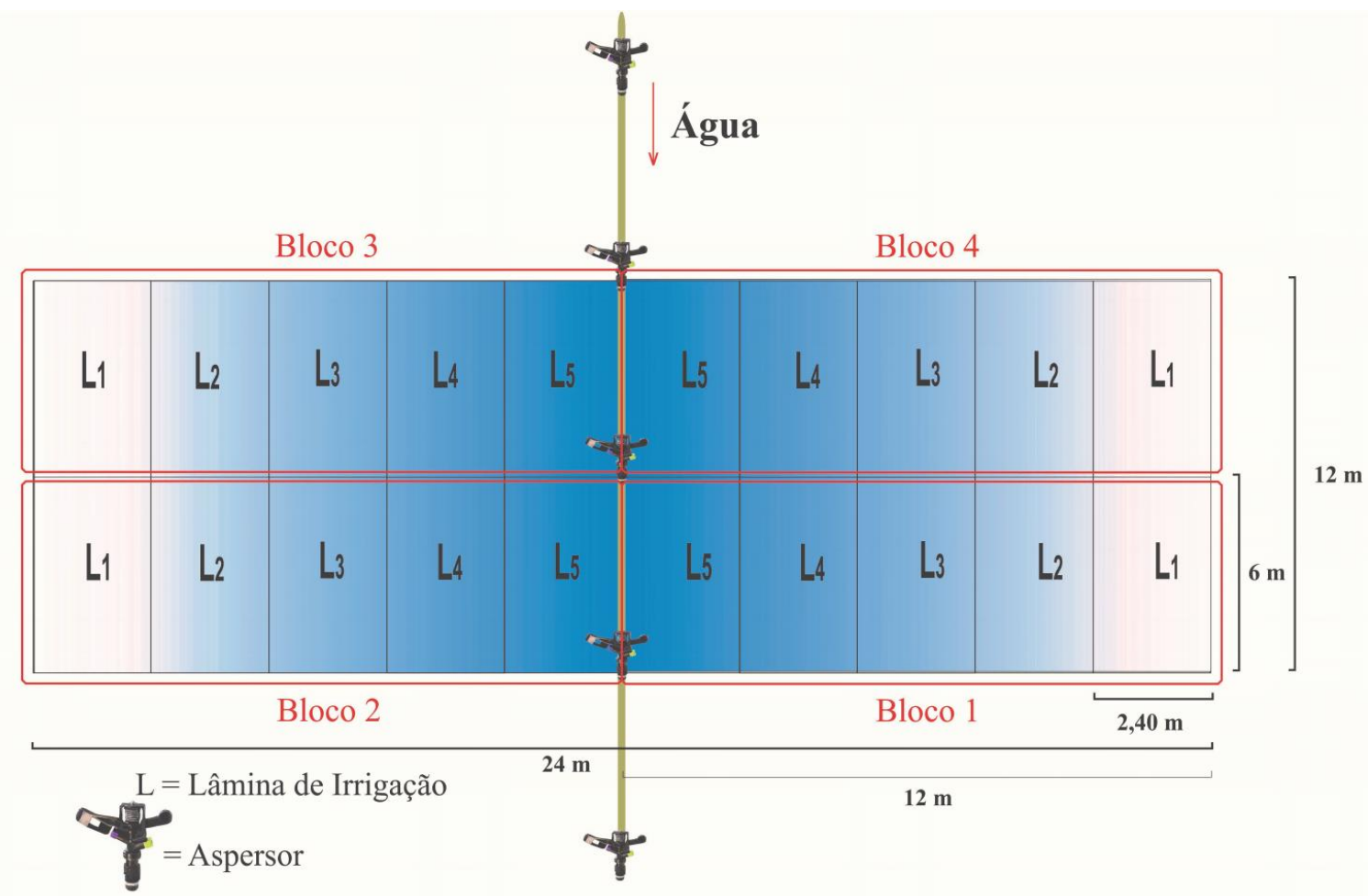

FIGURA 1. Esquema da área experimental, com linha de distribuição de água e unidades experimentais com tratamentos de lâminas de irrigação ( $\mathrm{L}_{1}$ a $\left.\mathrm{L}_{5}\right)$. Experimental area diagram showing water distribution lines and experimental units under different water depths $\left(L_{1}\right.$ to $\left.L_{5}\right)$.

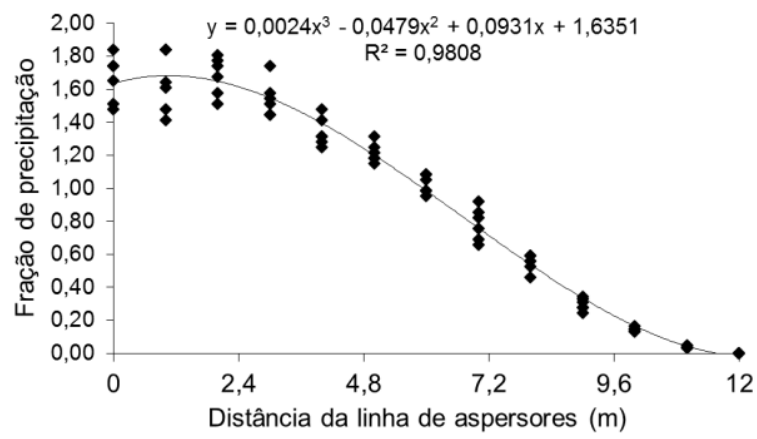

\begin{tabular}{ccc}
\hline $\begin{array}{c}\text { Distância } \\
(\mathrm{m})\end{array}$ & Tratamento & $\begin{array}{c}\text { Fator de } \\
\text { distribuição } \\
\text { do } \\
\text { precipitado }\end{array}$ \\
\hline $0,0-2,4$ & $\mathrm{~L}_{5}$ & 1,67 \\
$2,4-4,8$ & $\mathrm{~L}_{4}$ & 1,45 \\
$4,8-7,2$ & $\mathrm{~L}_{3}$ & 1,00 \\
$7,2-9,6$ & $\mathrm{~L}_{2}$ & 0,52 \\
$9,6-12,0$ & $\mathrm{~L}_{1}$ & 0,18 \\
\hline
\end{tabular}

FIGURA 2. Fração de distribuição da precipitação de aspersores Senninger, modelo 3023-2, com duplo bocal de 8 x 5 mm, em função da distância ou tratamentos da linhas de irrigação, com aspersores espaçados de $6 \mathrm{~m}$ na linha lateral. Precipitation profile of Senninge $\mathbf{r}$ sprinklers, 3023-2 model, with double nozzle heads $(8 \times 5 \mathrm{~mm})$ according to distance or treatment of irrigation lines with nozzles spaced in $6 \mathrm{~m}$ along lateral line.

A evapotranspiração de referência foi calculada pelo método Penman-Monteith (ALLEN et al., 1998) com dados meteorológicos diários coletados na Estação Agroclimatológica da FCAVUNESP, localizada próximo da área experimental.

A pastagem foi formada em novembro de 2012 com Brachiaria brizantha cv. Marandu e, em 29-04-2014, sofreu corte de uniformização a $15 \mathrm{~cm}$ de altura do solo. Para atender ao critério nutricional, adotou-se o tratamento $\mathrm{L}_{5}$ como referência para os demais tratamentos e aplicaram-se $15 ; 3,5$ e $18 \mathrm{~kg} \mathrm{ha}^{-1}$ de $\mathrm{N}, \mathrm{P}_{2} \mathrm{O}_{5}$ e $\mathrm{K}_{2} \mathrm{O}$, respectivamente, para cada tonelada de massa seca produzida na colheita anterior, conforme proposto por VILELA et al. (1998). Todos os fertilizantes foram distribuídos manualmente, imediatamente após a colheita da braquiária (PREMAZZI et al., 2003). 
O monitoramento de umidade do solo foi realizado por sonda de nêutrons (CPN, modelo 503 DR Hydroprobe), previamente calibrada para o local. As leituras foram realizadas em tubos de ferro (galvanizado) com $120 \mathrm{~cm}$ de profundidade em duas repetições para cada lâmina de irrigação, com medidas semanais tomadas a 0-20; 20-40; 40-60; 60-80 e 80-100 cm de profund idade.

A altura da planta foi monitorada semanalmente com auxílio de uma régua graduada em centímetros, e uma folha de transparência (filme de acetato), posicionada sobre o dossel, medindose a altura do solo até o ponto médio da transparência (SOUZA JÚNIOR, 2007; FAGUNDES et al., 1999). As medidas foram tomadas em seis posições da parcela escolhidas aleatoriamente.

O experimento foi conduzido de 29-04-2014 a 19-08-2014, sendo realizadas quatro colheitas de forragem, duas no outono e duas no inverno. Em cada colheita, foram tomadas três amostras de $0,25 \mathrm{~m}^{2}$ em cada parcela, utilizando-se de um gabarito de aço galvanizado de $0,5 \times 0,5 \mathrm{~m}$, com suportes para mantê- lo a $15 \mathrm{~cm}$ de altura do solo. A forragem foi cortada a $15 \mathrm{~cm}$ do nível do solo, com um cutelo, e homogeneizada, e, a seguir, determinada a biomassa verde e seca em estufa com circulação forçada de ar, a $65^{\circ} \mathrm{C}$ até peso constante, em aproximadamente 48 horas. A colheita no restante da parcela foi realizada com roçadora manual.

Amostras compostas de tecidos vegetais coletados em 25-06 e 20-08 de 2014 foram analisadas para determinar teores de proteína bruta (PB) e fibra em detergente neutro (FDN), conforme proposto por SILVA \& QUEIROZ (2006).

As produtividades de massa seca produzida nos tratamentos irrigados nos cortes do outo no e de inverno foram totalizadas por estação e submetidas à análise de variância e comparação de médias, segundo o modelo de JOHNSON et al. (1983), para o sistema de aspersão em linha pelo programa SAS (SAS Institute, 1995). Foram ajustadas funções de resposta entre a produtividade de massa seca e a lâmina de irrigação.

\section{RESULTADOS E DISCUSSÃO}

A temperatura e a radiação solar diária ocorreram dentro da faixa de variações históricas (29 anos) da região para o outono e o inverno (Figura 3). Assim, os valores de temperatura média foram de $20,5^{\circ} \mathrm{C}$ em maio e junho, decresceram para $19,5^{\circ} \mathrm{C}$ em julho e depois aumentaram para $22,1^{\circ} \mathrm{C}$ em agosto. As médias das temperaturas máximas e mínimas seguiram a mesma tendência, com cerca de 27,5 e $14{ }^{\circ} \mathrm{C}$ em maio e junho, 26,5 e $13{ }^{\circ} \mathrm{C}$ em julho e 30,5 e $14{ }^{\circ} \mathrm{C}$ em agosto, respectivamente. Os valores absolutos de temperatura mínima foram menores que $15{ }^{\circ} \mathrm{C}$ na maioria do período experimental, porém temperaturas abaixo de $10{ }^{\circ} \mathrm{C}$ ocorreram em apenas 6 dias (Figura 3).

A evapotranspiração de referência média seguiu o curso da variação de temperatura e radiação solar, ou seja, foi de $3 \mathrm{~mm}$ em maio e junho, decresceu para 2,8 $\mathrm{mm}$ em julho e subiu para 4,5 $\mathrm{mm}$ em agosto (Figura 3). Durante o período experimental, a evapotranspiração de referência totalizou $357 \mathrm{~mm}$, enquanto a precipitação foi de $39 \mathrm{~mm}$.

A irrigação constituiu o maior aporte hídrico às plantas, sendo realizadas 19 aplicações, com lâminas acumuladas variando de 35 a $319 \mathrm{~mm}$ no outono e de 21 a $193 \mathrm{~mm}$ no inverno, para os tratamentos $\mathrm{L}_{1}$ a $\mathrm{L}_{5}$, respectivamente (Tabela 2). 
a)

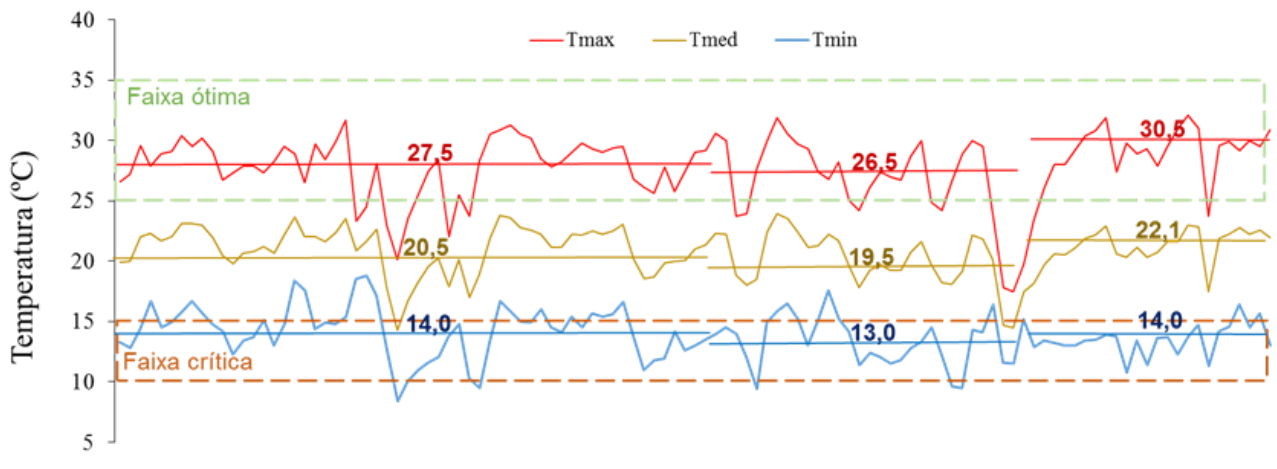

b)

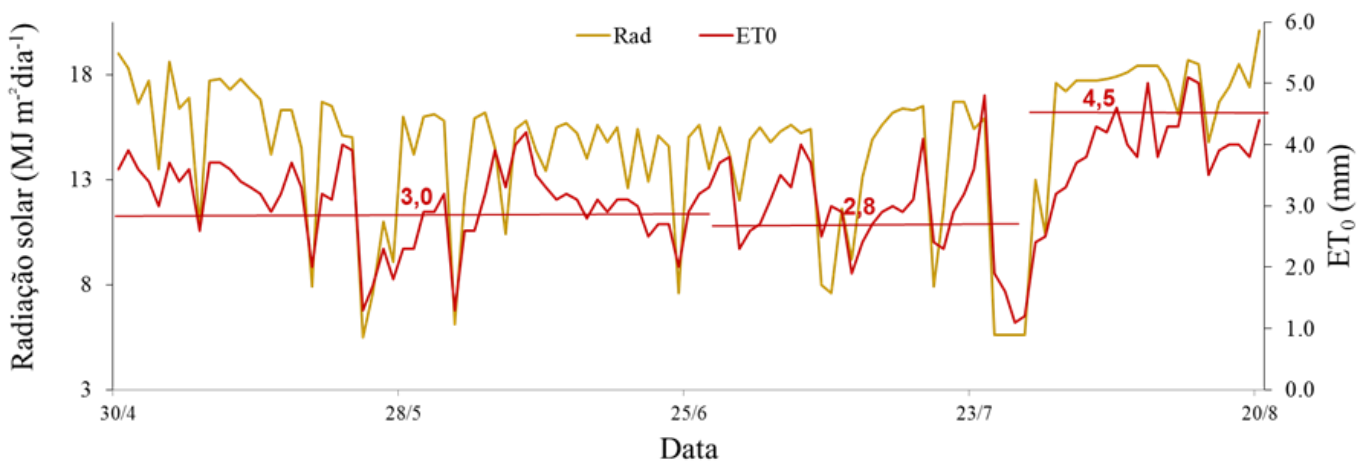

FIGURA 3. Temperaturas máxima (Tmáx), média (Tméd) e mínima (Tmín), radiação solar (Rad) e evapotranspiração de referência $\left(\mathrm{ET}_{0}\right)$, durante outono e inverno de 2014, em Jaboticabal-SP. Maximum (Tmax), medium (Tmed) and minimum (Tmin) temperatures, solar radiation (Rad), and reference evapotranspiration $\left(\right.$ ET $\left._{0}\right)$ during the autumn and winter of 2014, in Jabotica bal - SP, B razil.

TABELA 2. Precipitação, irrigação e lâmina total (irrigação + precipitação) aplicada na Brachiaria brizantha durante o outono e o inverno de 2014, em Jaboticabal-SP. Rainfall (Prec.), irrigation depth and full depth (irrigation + rainfall) in Brachiaria brizantha pasture during the autumn and winter of 2014, in Jaboticabal - SP, B razil.

\begin{tabular}{lcrrrrrr}
\hline \multirow{2}{*}{ Período } & \multirow{2}{*}{ Corte } & \multirow{2}{*}{ Prec. } & \multicolumn{5}{c}{ Irrigação (mm) } \\
\cline { 4 - 8 } & & & $\mathrm{L}_{1}$ & \multicolumn{1}{c}{$\mathrm{L}_{2}$} & \multicolumn{1}{c}{$\mathrm{L}_{3}$} & \multicolumn{1}{c}{$\mathrm{L}_{4}$} & \multicolumn{1}{c}{$\mathrm{L}_{5}$} \\
\hline \multirow{2}{*}{ Outono } & 1 & 7 & 22 & 63 & 124 & 179 & 205 \\
& 2 & 2 & 12 & 35 & 69 & 100 & 114 \\
\hline \multirow{2}{*}{ Inverno } & Soma & 9 & 35 & 98 & 192 & 279 & 319 \\
\hline & 4 & 7 & 10 & 24 & 55 & 80 & 91 \\
& 4 & 23 & 11 & 27 & 62 & 89 & 102 \\
\hline & Soma & 30 & 21 & 52 & 116 & 169 & 193 \\
\hline & Total & 39 & 56 & 150 & 309 & 448 & 512 \\
\hline
\end{tabular}

\begin{tabular}{rrrrr}
\hline \multicolumn{5}{c}{ Lâmina total (mm) } \\
\hline $\mathrm{L}_{1}$ & $\mathrm{~L}_{2}$ & \multicolumn{1}{c}{$\mathrm{L}_{3}$} & \multicolumn{1}{l}{$\mathrm{L}_{4}$} & \multicolumn{1}{c}{$\mathrm{L}_{5}$} \\
\hline 29 & 70 & 130 & 186 & 212 \\
14 & 37 & 71 & 101 & 116 \\
\hline 43 & 106 & 201 & 287 & 328 \\
\hline 17 & 31 & 62 & 86 & 98 \\
35 & 51 & 85 & 113 & 125 \\
\hline 51 & 82 & 147 & 199 & 223 \\
\hline 95 & 188 & 348 & 486 & 551 \\
\hline
\end{tabular}

As determinações de umidade no perfil do solo revelaram disponibilidade hídrica acima de $50 \%$ da água disponível ( $\mathrm{AD}$ ) para os tratamentos $\mathrm{L}_{3}, \mathrm{~L}_{4} \mathrm{e} \mathrm{L}_{5}$, que receberam lâminas iguais ou maiores que a evapotranspiração de referência $\left(\mathrm{ET}_{0}\right)$ (Figuras 4 e 5). $\mathrm{O}$ tratamento $\mathrm{L}_{2}$ apresentou retenção de água entre 20 e $50 \%$ da água disponível, e o $\mathrm{L}_{1}$ manteve-se com retenção de água em torno do limite inferior de água disponível, uma vez que receberam lâminas inferiores da evapotranspiração de referência (Figuras 4 e 5). A maior quantidade de água no solo durante o início do experimento pode ser atribuída às chuvas ocorridas no período antecedente. 
a)

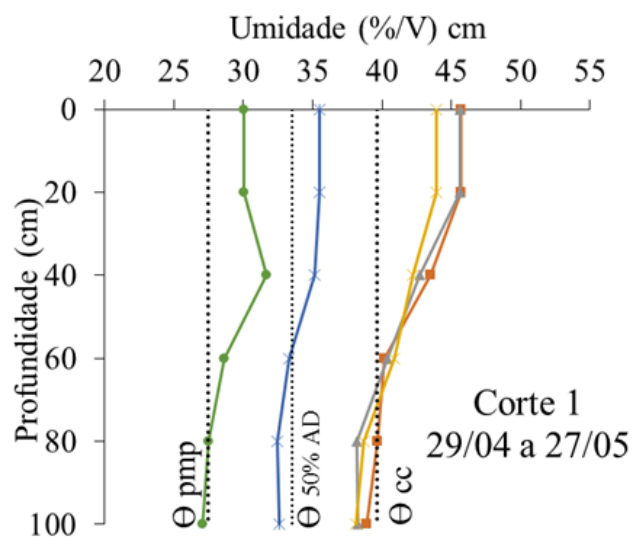

c)

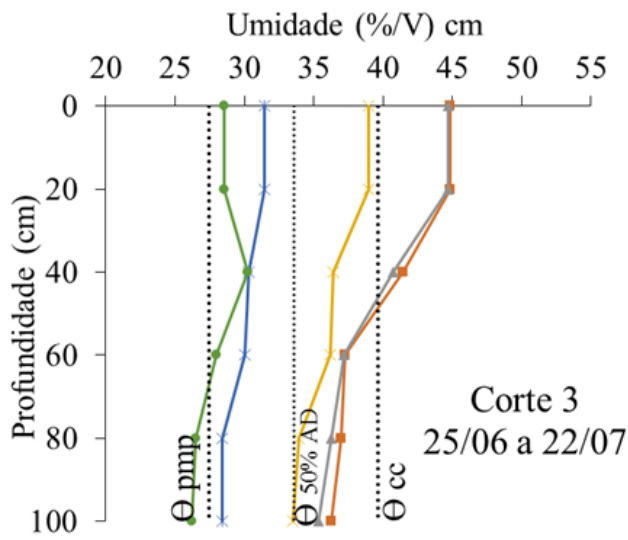

b)

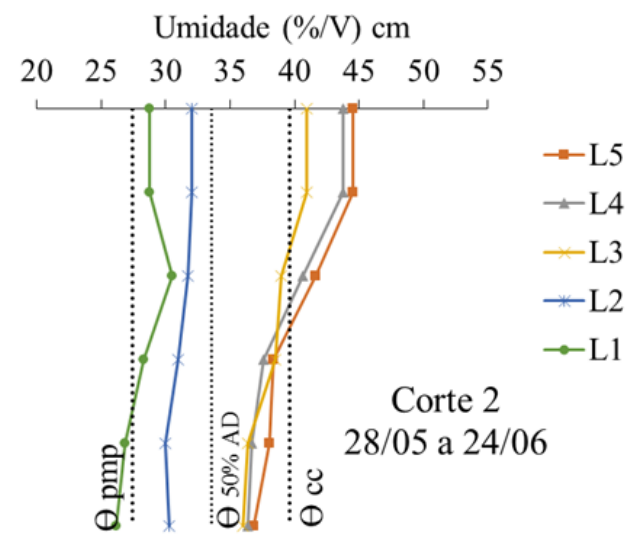

d)

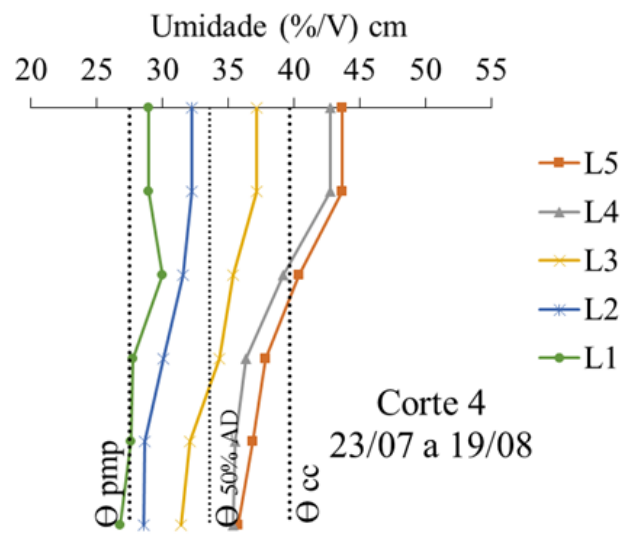

FIGURA 4. Umidade volumétrica do solo média em função das lâminas de irrigação ( $\mathrm{L}_{1}$ a $\left.\mathrm{L}_{5}\right)$, durante o período entre cortes da forragem, no outono (a,b) e no inverno de 2014 (c, d), em Jaboticabal-SP. Mean soil volumetric moisture according to irrigation depth $\left(L_{1}\right.$ to $\left.L_{5}\right)$ within the period between forage cuts in the autumn $(a, b)$ and in the winter (c, d) of 2014, in Jaboticabal - SP, B razil.

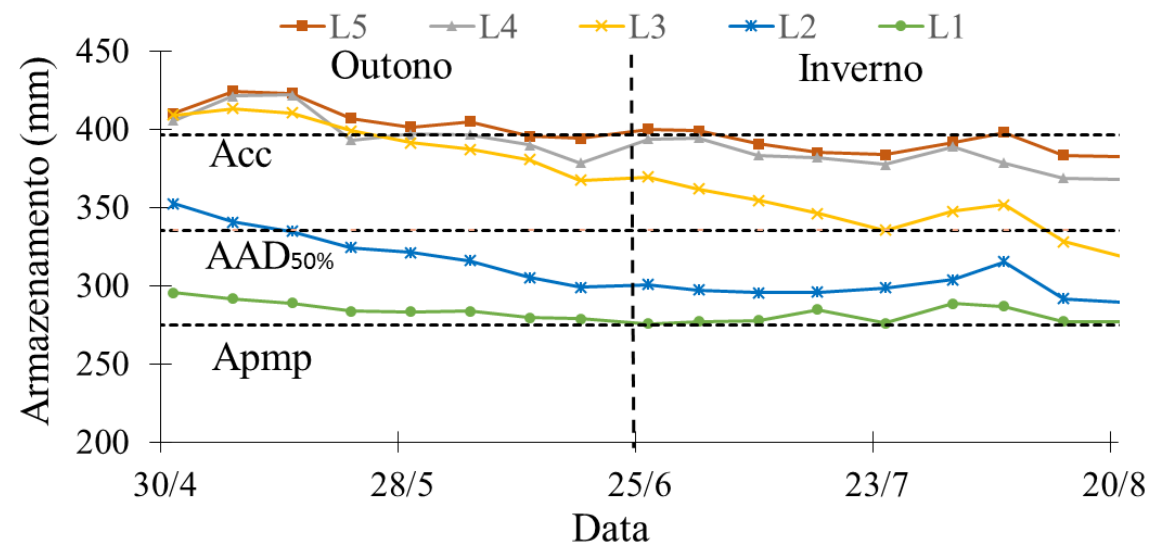

FIGURA 5. Armazenamento de água no solo $(0-100 \mathrm{~cm})$ em função das lâminas de irrigação $\left(\mathrm{L}_{1}\right.$ a L5), durante o outono e o inverno de 2014, em Jaboticabal-SP. Acc = armazenamento de água na capacidade de campo do solo; Apmp = armazenamento de água no ponto de murcha permanente do solo e $\mathrm{AAD}_{50 \%}=50 \%$ do armazenamento de água disponível. Soil water storage $(0-100 \mathrm{~cm})$ for each irrigation depth $\left(L_{1}\right.$ to $\left.L_{5}\right)$ during the autumn and winter of 2014, in Jaboticabal $-\mathrm{SP}$, B razil. Acc $=$ soil water storage at field capacity; $A P M P=$ soil water storage at wilting point, and $\mathrm{AAD}_{50 \%}=\mathbf{5 0 \%}$ available water storage. 
As alturas médias do dossel e as produtividades de forragem foram maiores no outono, no primeiro corte, e decresceram à medida que se avançou para o inverno, com menores alturas e produtividades no corte 4 (Figura 6). Esse efeito foi ocasionado por temperaturas mais elevadas em maio e junho e menor temperatura em julho, conforme apresentado na Figura 3. Devido à Brachiaria brizantha ser uma espécie tropical, tais resultados corroboram vários autores, que afirmam que espécies forrageiras tropicais têm crescimento ótimo dentro de uma faixa de temperatura entre 25 a $35^{\circ} \mathrm{C}$ e seu crescimento é reduzido até cessar sua atividade sob temperaturas entre 10 e $15^{\circ} \mathrm{C}$ (COOPER \& TAINTON, 1968; DRUMOND \& AGUIAR, 2005). Sendo assim, a temperatura é um dos principais fatores responsáveis pela estacionalidade da produção das pastagens, conforme TONATO (2003).

A altura e a produtividade da forragem variaram também com a lâmina de irrigação aplicada (Figura 6). Nos tratamentos com dotação hídrica menor que $\mathrm{ET}_{0}, \mathrm{~L}_{1}$ a $\mathrm{L}_{2}$, o crescimento e a produtividade foram drasticamente reduzidos, sobretudo no segundo e terceiro cortes, em junho e julho, especialmente no tratamento $\mathrm{L}_{1}$. Nesse caso, a altura do dossel não ultrapassou o limite de altura do pós-pastejo de $15 \mathrm{~cm}$, ou seja, não houve crescimento da cultura. No último corte, em 20 de agosto, houve produção de forragem de cerca de $800 \mathrm{~kg} \mathrm{ha}^{-1}$ nos tratamentos $\mathrm{L}_{1}$ e $\mathrm{L}_{2}$ devido à ocorrência de precipitação de $23 \mathrm{~mm}$ e ligeiro acréscimo de temperatura em relação a julho. Nos tratamentos com aplicações de lâminas de irrigação acima de $\mathrm{ET}_{0}, \mathrm{~L}_{3}, \mathrm{~L}_{4} \mathrm{e} \mathrm{L}_{5}$, as alturas de corte foram similares, e a produtividade de forragem atingiu valores próximos. Os resultados indicam que a Brachiaria brizantha exige a manutenção do armazenamento de água no solo acima de $50 \%$ da água disponível no período de outono e inverno para suprir suas necessidades hídricas, conco rdando com MELO et al. (2009), que também encontraram maior produção de forragem de capinsmo mbaça e marandu em solo com disponibilidade hídrica acima de $50 \%$ da água disponível.
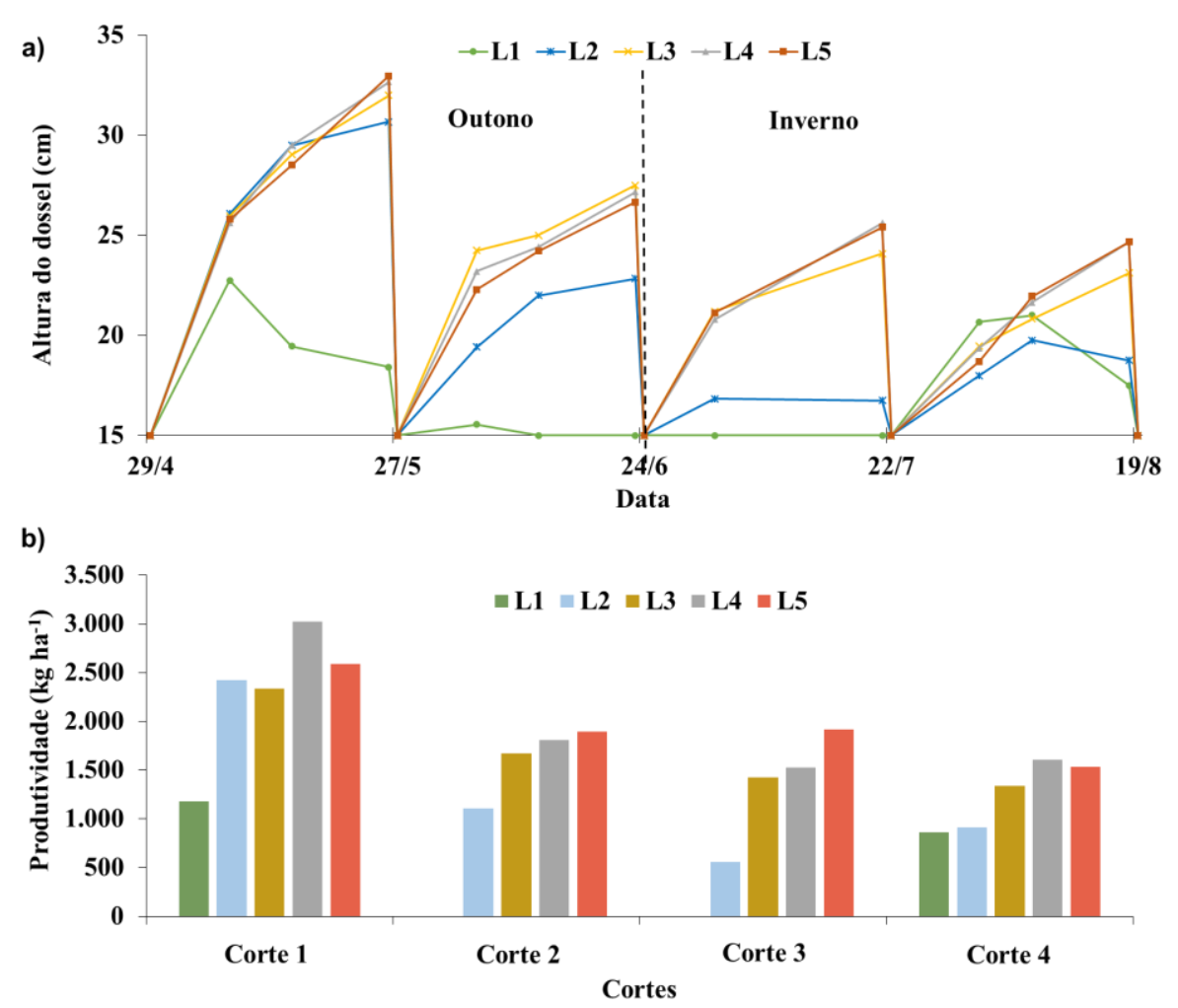

FIGURA 6. Altura média do dossel (a) e produtividade de matéria seca de forragem de Brachiaria brizantha (b), em função da lâmina de irrigação e do período de corte durante o outono e o inverno de 2014, em Jaboticabal-SP. Mean canopy height (a) and dry matter yield of Brachiaria brizantha forage (b) according to water depth and cut period during the autumn and winter of 2014, in Jaboticabal - SP, B razil. 
A análise de variância dos dados de produtividade de massa seca de forragem revelou efeito significativo das lâminas de irrigação e das estações do ano analisadas $(\mathrm{P}<0,05)$, não havendo interação entre esses fatores (Tabela 3). O outono apresentou produtividade significativamente superior à do inverno. Constatou-se menor produtividade no tratamento com lâmina $\mathrm{L}_{1}$ e maiores produtividades nas lâminas $\mathrm{L}_{3}, \mathrm{~L}_{4}$ e $\mathrm{L}_{5}$, porém o tratamento com lâmina $\mathrm{L}_{2}$ não diferiu do tratamento com lâmina $\mathrm{L}_{3}$.

TABELA 3. Resumo da análise de variância (ANOVA) e comparação de médias de produtividade de massa seca (MS) de Brachiaria brizantha $\left(\mathrm{kg} \mathrm{ha}^{-1}\right)$, pelo teste de Tukey, em função das lâminas totais (irrigação + precipitação), no outono e no inverno de 2014, em Jaboticabal-SP. Summary of variance analysis (ANOVA) and means of dry mass yield (DM) for Brachiaria brizantha $\left(\mathrm{kg} \mathrm{ha}^{-1}\right)$, compared by the Tukey's test, according to total water (irrigation + rainfall) in the autumn and winter of 2014, in Jaboticabal - SP, B razil.

\begin{tabular}{|c|c|c|c|}
\hline \multirow{2}{*}{ Fonte de Variação } & \multirow{2}{*}{ GL } & \multicolumn{2}{|c|}{ Quadrado Médio } \\
\hline & & \multicolumn{2}{|c|}{ Prod. (MS) } \\
\hline Bloco (B) & 3 & \multicolumn{2}{|c|}{$7,51 \mathrm{E}+04^{\mathrm{ns}}$} \\
\hline Estação (E) & 1 & \multicolumn{2}{|c|}{$4,05 \mathrm{E}+06^{* *}$} \\
\hline Int. E X B & 3 & \multicolumn{2}{|c|}{$1,07 \mathrm{E}+04^{\mathrm{ns}}$} \\
\hline Lâmina (L) & 4 & \multicolumn{2}{|c|}{$3,10 \mathrm{E}+06^{* *}$} \\
\hline Int. EX L & 4 & \multicolumn{2}{|c|}{$2,22 \mathrm{E}+05^{\mathrm{ns}}$} \\
\hline CV $(\%)$ & & \multicolumn{2}{|c|}{21,0} \\
\hline Estação & \multicolumn{3}{|l|}{ Média } \\
\hline Outono & \multicolumn{3}{|l|}{$1.804 .2 \mathrm{a}$} \\
\hline Inverno & \multicolumn{3}{|l|}{$1.167 .8 \mathrm{~b}$} \\
\hline \multirow{2}{*}{ Lâmina } & \multicolumn{3}{|c|}{$\left(\mathrm{kg} \mathrm{ha}^{-1}\right)$} \\
\hline & Outono & Inverno & Média \\
\hline $\mathrm{L}_{1}$ & 591 & 431 & $511 \mathrm{c}$ \\
\hline $\mathrm{L}_{2}$ & 1.768 & 736 & $1.252 \mathrm{~b}$ \\
\hline $\mathrm{L}_{3}$ & 2.003 & 1.380 & $1.692 \mathrm{ab}$ \\
\hline $\mathrm{L}_{4}$ & 2.417 & 1.567 & $1.992 \mathrm{a}$ \\
\hline $\mathrm{L}_{5}$ & 2.243 & 1.725 & $1.984 \mathrm{a}$ \\
\hline
\end{tabular}

GL - grau de liberdade; Significativo a $0,05\left(^{\prime \prime}\right)$ e a $0,01(")$ de probabilidade; $\left({ }^{\text {ns }}\right)$ não significativo;

CV - coeficiente de variação; médias seguidas de mesma letra não diferem entre si $(p<0,05)$, pelo teste de Tukey.

A função de resposta entre a produtividade de massa seca e a lâmina total (lâmina + precipitação) apresentou comportamento quadrático, tanto para o outono, quanto para o inverno (Figura 7). A eficiência de uso de água, dada em $\mathrm{kg}$ de forragem por $\mathrm{mm}$ de lâmina de água aplicada, foi maior no outono, tendo em vista os valores mais elevados de produtividade para a função ajustada para esta estação. A produtividade de forragem foi crescente até atingir produtividades máximas de $2.359 \mathrm{~kg} \mathrm{ha}^{-1}$ no outono e $1.756 \mathrm{~kg} \mathrm{ha}^{-1}$ no inverno. Produtividades máximas de forragem foram obtidas com aplicações de lâminas de 267 e $269 \mathrm{~mm}$ para o outono e o inverno, respectivamente. Tal comportamento de resposta em forrageiras foi também observado por ALENCAR et al. (2009b), LOPES et al. (2014) e DUPAS et al. (2010).

De acordo com os resultados da Tabela 3 e Figura 6, em 4 cortes, aos 120 dias, no período de outono/inverno, a irrigação proporcionou acréscimo da produção total de forragem de $1.022 \mathrm{~kg} \mathrm{ha}^{-1}$ no tratamento $\mathrm{L}_{1}$ para $3.968 \mathrm{~kg} \mathrm{ha}^{-1}$ no tratamento $\mathrm{L}_{5}$, correspondente ao incremento de $288 \%$. 


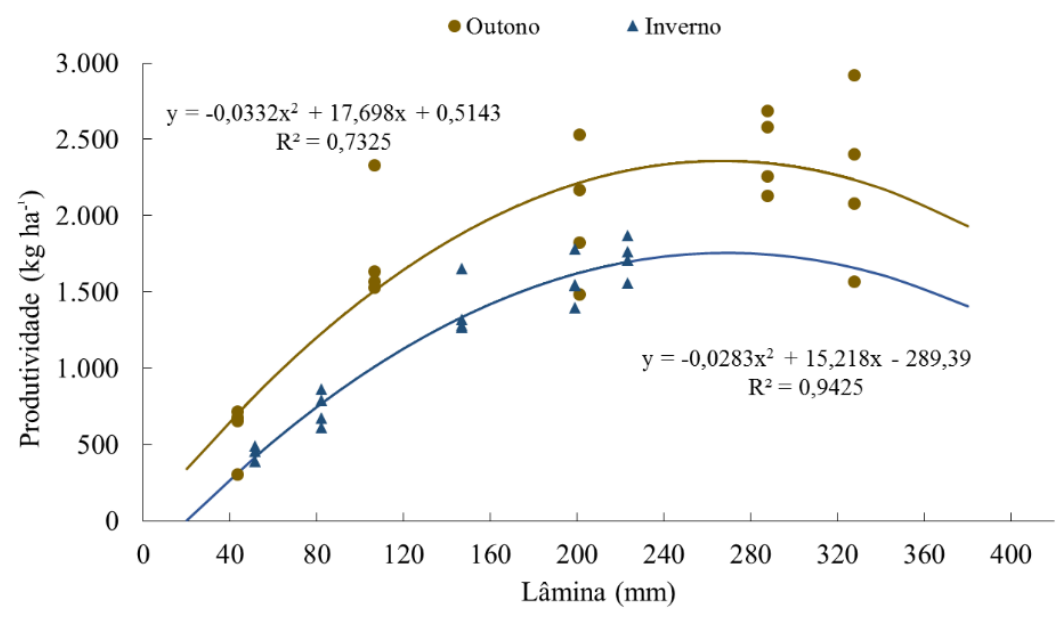

FIGURA 7. Produtividade de matéria seca de forragem de Brachiaria brizantha em função das lâminas de água recebidas pela cultura, no outono e no inverno de 2014, em Jaboticabal-SP. Forage dry matter yield of Brachiaria brizantha in function of the water depth supplied in the autumn and winter of 2014, in Jaboticabal - SP, Brazil.

Alto valor nutritivo da forragem, caracterizado por elevados teores de proteína bruta (PB) e baixos teores de fibra em detergente neutro (FDN), foi obtido em ambas as estações do ano (Tabela 4).

TABELA 4. Teores de Proteína bruta (PB) e fibra em detergente neutro (FDN) \% de massa seca (MS), na folha e colmo da Brachiaria brizantha em função das lâminas de irrigação, no outono e no inverno em 2014, em Jaboticabal-SP. Contents of crude protein (CP) and neutral detergent fiber (NDF) (in \% of DM) analyzed in Brachiaria brizantha leaves and stems for each irrigation depth in the autumn and winter of 2014, in Jaboticabal - SP, B razil.

\begin{tabular}{|c|c|c|c|c|c|c|}
\hline Estação & $\mathrm{L}_{1}$ & $\mathrm{~L}_{2}$ & $\begin{array}{c}\mathrm{L}_{3} \\
\mathrm{~PB}(\%)\end{array}$ & $\mathrm{L}_{4}$ & $\mathrm{~L}_{5}$ & Média \\
\hline Outono & 11,6 & 14,4 & 14,9 & 18,8 & 20,1 & 16,0 \\
\hline Inverno & 14,4 & 13,7 & 14,2 & 14,6 & 14,8 & 14,4 \\
\hline \multicolumn{7}{|c|}{ FDN (\%) } \\
\hline Outono & 56,5 & 56,5 & 54,7 & 53,7 & 58,0 & 55,9 \\
\hline Inverno & 55,4 & 54,2 & 55,7 & 56,0 & 54,7 & 55,2 \\
\hline
\end{tabular}

No outono, houve incremento nos teores de PB, de 11,6 a 20,1\%, com o acréscimo da lâmina de irrigação de $\mathrm{L}_{1}$ a $\mathrm{L}_{5}$ (Tabela 4). No inverno, os teores de PB com as lâminas de irrigação aplicada foram similares. Os teores de FDN foram similares (53,7 a 56\%) em todos os tratamentos, nas duas estações do ano, exceto no tratamento $\mathrm{L}_{5}$ no outono, em que se obteve média de $58 \%$. GERDES et al. (2000), ao comparar o teor de PB Brachiaria brizantha durante as estações do ano, encontraram maiores teores no outono e no inverno, em relação aos demais períodos do ano. Os teores elevados de PB e baixos de FDN encontrados nesta pesquisa podem ser explicados pela menor velocidade de crescimento no outono e no inverno, em relação à de primavera e verão, o que resulta em maior produção de folhas do que hastes (ANDRADE, 2003; COSTA et al., 2007; SANTOS et al., 2009; SILVA et al., 2009). Como o teor de PB aumentou no outono ou manteve-se no inverno (Tabela 4) com o aumento da produtividade, em decorrência da irrigação (Tabela 3 e Figura 5), houve aumento na produção de PB por unidade de área. 


\section{CONCLUSÕES}

- A produtividade de forragem de Brachiaria brizantha foi mais elevado no outono, em relação ao inverno. A irrigação proporcionou aumento de cerca de $288 \%$ na produção de forragem, correspondente a $3.000 \mathrm{~kg} \mathrm{ha}^{-1}$, em 4 cortes realizados no período de cerca de quatro meses. Maiores produtividades foram obtidas com aplicação de lâminas de irrigação igual ou superior à evapotranspiração de referência, correspondentes aos tratamentos $\mathrm{L}_{3}, \mathrm{~L}_{4}$ e $\mathrm{L}_{5}$.

- A função de produção ajustada entre produtividade de forragem e lâmina de água mostrou comportamento quadrático, tanto para o outono, quanto para o inverno. A produtividade de forragem foi incrementada com o aumento da lâmina de irrigação, atingindo produtividade máxima com lâminas de 267 e 269 mm para o outono e o inverno, respectivamente.

- Alto valor nutritivo da forragem, caracterizado por elevados teores de PB (16\%) e baixos teores de FDN (55\%), foi obtido em ambas as estações do ano. Incrementos nos teores de PB com o acréscimo da lâmina de irrigação ocorreram somente no outono. Os teores de FDN da forragem nas estações estudadas variaram muito pouco com as lâminas aplicadas.

- A Brachiaria brizantha requer a manutenção do armazenamento de água no solo acima de 50\% da água disponível no período de outono e de inverno para suprir suas necessidades hídricas.

- Temperaturas subótimas durante o inverno limitaram a produtividade de forragem, mesmo nos tratamentos com maior suprimento hídrico.

\section{REFERÊNCIAS}

ALENCAR, C.A.B.; CÓSER, A.C.; MARTINS, C.E.; OLIVEIRA, R.A. Altura de capins e cobertura do solo sob adubação nitrogenada, irrigação e pastejo nas estações do ano irrigação e pastejo nas estações do ano. Acta Scientiarum, Agronomy, Maringá, v. 32, n.1, p. 21-27, 2010.

ALENCAR, C.A.B.; CUNHA, F.F.; MARTINS, C.E. Irrigação de pastagem: atualidade e recomendações para uso e manejo. Revista Brasileira de Zootecnia, Viçosa, MG, v.38, p.98-108, 2009a. Suplemento Especial.

ALENCAR, C.A.B; CÓSER, A.C.; OLIVEIRA, R.A.; MARTINS, C.E.; CUNHA, F.F.; FIGUEIREDO, J.L.A. Prod ução de seis gramíneas manejadas por corte sob efeito de Diferentes lâminas de irrigação e estações anuais. Ciência Agrotetecnológica, Lavras, v.33, n.5, p.1307-1313, 2009b.

ALLEN, R.G.; PEREIRA, L.S.; RAES, D.; SMITH, M. Crop evapotranspiration - Guidelines for computing crop water require ments. Rome: FAO. 1998. 300p. (Irrigation and Drainage Paper 56).

ANDRADE, F.M.E. Produção de forragem e valor alimentício do capim-marandu submetido a regimes de lotação contínua por bovino de corte. 2003. 125f. Dissertação (Mestrado em Agronomia) - Escola Superior de Agricultura Luiz de Queiroz, Universidade de São Paulo, Piracicaba, 2003.

ANDRIOLI, I.; CENTURION, J.F. Levantamento detalhado dos solos da Faculdade de Ciências Agrárias e Veterinárias de Jaboticabal. In: Congresso Brasileiro de Ciência do Solo, 27, 1999, Brasília. Anais... Sociedade Brasileira de Ciência do Solo, 32p. CD-ROM.

COOPER, J.P.; TAINTON, N.M. Light and temperature requeriments for growth of tropical and temperate grasses. Review article. Herbage Abstracts, Wallingford, v.38, p.167-176, 1968.

COSTA, K.A. de P.; OLIVEIRA, I.P. de; FAQUIN, V.; NEVES, B.P. das; RODRIGUÊS, C.; SAMPAIO, F. de M. Intervalo de corte na produção de massa seca e composição químicobromatológico da Brachiaria brizantha cv. MG-5. Ciência Agrotetecnológica, Lavras, v.31, n.4, p.1197-1202, 2007.

DIAS-FILHO, M. B. Diagnóstico das pastagens no Brasil. Belém: Embrapa Amazônia, 2014. 
DRUMOND, L. C. D.; AGUIAR, A. P. A. Irrigação de pastagens. Uberaba: FAZU, 2005.

DUPAS, E.; BUZETTI, S.; SARTO, A.L.; HERNANDEZ, F.B.T.; BERGAMASCHINE, A.F. Dry matter yield and nutritional value of Marandu grass under nitrogen fertilization and irrigation in cerrado in São Paulo. Revista Brasileira de Zootecnia, Viçosa, MG, v.39, n.12, p.2598-2603, 2010.

FAGUNDES, J.L.; SILVA, S.C.; PEDREIRA, C.G.S.; SBRISSIA, A.F.; CARNEVALLI, R.A.; CARVALHO, C.A.B.; PINTO, L.F.M. Índ ice de área foliar, interceptação luminosa e Acúmulo de forragem em pastagens de cynodon spp. Sob diferentes intensidades de pastejo. Scientia Agricola, Piracicaba, v.56, n.4, p.1141-1150, 1999.

GERDES, L.; WERNER, J.C.; COLOZZA, M.T.; POSSENTI, R.A.; SCHMMASS, E.A. Avaliação de características de valor nutritivo das gramíneas forrageiras Marandu, Setária e Tanzânia nas estações do ano. Revista Brasileira de Zootecnia, Viçosa, MG, v.29, n.4, p.955-963, 2000.

IBGE - INSTITUTO BRASILEIRO DE GEOGRAFIA e ESTATÍSTICA. Censo Agropecuário 2006. Brasília, 2007. Disponível em: <www.ibge.org.br>. Acesso em: 23 out. 2014.

JOHNSON, D.E.; CHAUDHURI, U.N.; KANEMASU, E.T. Statistical analysis of linesourcesprinkler experiments and other nonrandomized experiments using multivariate methods. Soil Science Societyof America Journal, Madison, v.47, p.309-312, 1983.

LOPES, M.N.; POMPEU, R.C.F.F.; SILVA, R.G.; REGADAS FILHO, J.G.L.; LACERDA, C.F.; BEZERRA, M.A. Fluxo de biomassa e estrutura do dossel em capim braquiária manejado, sob lâminas de irrigação e idades de crescimento. Bioscience Journal, Uberlândia, v.30, n.2, p.490$500,2014$.

MELO, J.C.; SANTOS, A.C.; ALMEIDA, J.A.; MORAIS NETO, L.R. Desenvolvimento e produtividade dos capins mombaça e marandu cultivadas em dois solos típicos do Tocantins com diferentes regimes hídricos. Revista Brasileira de Saúde e Produção Animal, Salvador, v.10, n. 4, p.786-800, 2009.

MAPA - Ministério da Agricultura, Pecuária e Abastecimento. Plano mais pecuária. Brasília: MAPA/ACS, 2014.

PREMAZZI, L.M.; MONTEIRO, F.A.; CORRENTE, J.E. Perfilhamento de tifton 85, em resposta a doses de nitrogênio e épocas de aplicação após o corte. Scientia Agricola, Piracicaba, v.60, n.3, p.565-571, 2003.

RODRIGUES, D. C. Produção de forragem de cultivares de Brachiaria brizantha (Hochst. ex A. Rich.) Stapf. e modelagem de respostas produtivas em função de variáveis climáticas . 2004. 94f. Tese de Doutorado. Dissertação (Mestrado) - Escola Superior de Agricultura Luiz de Queiroz, Universidade de São Paulo, Piracicaba, 2004.

ROLIM, G.S.; CAMARGO, M.B.P.; LANIA, D.G.; MORAES, J.F.L. Classificação climática de Köppen e de Thornthwaite e sua aplicabilidade na determinação de zonas agroclimáticas para o estado de São Paulo. B ragantia, Campinas, v.66, n.4, p.711-720, 2007.

SANTOS, M.E.R.; FONSECA, D.M.; BALBINO, E.M.; MONNERAT, J.P.I.S.; SILVA, S.P. Capim-braquiária diferido e adubado com nitrogênio: produção e características da forragem. Revista Brasileira de Zootecnia, Viçosa, MG, v.38, n.4, p.650-656, 2009.

SAS INSTITUTE. Statistical analysis system for Windows: computer program manual. Cary, 1995. 705p.

SILVA, D.J.; QUEIROZ, A.C. Análise de alimentos: métodos químicos e biológicos. 3. ed. Viçosa: UFV, 2006. 235p.

SILVA, F.F.; SÁ, J.F.; SCHIO, A.R.; ÍTAVO, L.C.V.; SILVA, R.R.; MATEUS, R.G. Suplementação a pasto: disponibilidade e qualidade $\mathrm{x}$ níveis de suplementação $\mathrm{x}$ desempenho. Revista Brasileira de Zootecnia, Viçosa, MG, v.38, p.371-389, 2009. 
SOUZA JUNIOR, S. J. Estrutura do dossel, interceptação de luz e acúmulo de forrage m em pastos de capim-marandu submetidos a estratégias de pastejo rotativo por bovinos de corte. 2007. 122f. Dissertação (Mestrado em Agronomia) - Escola Superior de Agricultura Luiz de Queiroz, Universidade de São Paulo, Piracicaba, 2007.

TEIXEIRA, F.A.; BONOMO, P.; PIRES, A.J.V.; SILVA, F.F.; FRIES, D.D.; HORA, D.S. Produção anual e qualidade de pastagem de Brachiaria decumbens diferida e estratégias de adubação nitrogenada. Acta Scientia rum. Animal Sciences, Maringá, v.33, n.3, p.241-248, 2011.

TONATO, F. Determinação de parâmetros produtivos de Cynodon spp. Em função de variáveis climáticas. 2003. 85f. Dissertação (Mestrado em Agronomia) - Escola Superior de Agricultura Luiz de Queiroz, Universidade de São Paulo, Piracicaba, 2003.

UNESP - UNIVERSIDADE ESTADUAL PAULISTA. Dados climáticos diários. Disponível em: <http://www.fcav.unesp.br/>. Acesso em: 5 jan. 2014.

VILELA, L.; SOARES, W.V.; SOUSA, D.M.G. DE; MACEDO, M.C.M. Calagem e adubação para pastagens na região do ce rrado. Planaltina: Embrapa Cerrados, 1998.15p. (Circular Técnica, 37).

VITOR, C.M.T.; FONSECA, D.M; CÓSER, A.C., MARTINS, C.E.; NASCIMENTO JÚNIOR, D.; RIBEIRO JÚNIOR, J.I. Produção de matéria seca e valor nutritivo de pastagem de capim-elefante sob irrigação e adubação nitrogenada. Revista Brasileira de Zootecnia, Viçosa, MG, v.38, n.3, p.435-442, 2009. 


\section{ERRATA}

No artigo "PRODUTIVIDADE E QUALIDADE DA BRACHIARIA IRRIGADA NO OUTONO/INVERNO”, com número de DOI: 10.1590/1809-4430-Eng.Agric.v36n3p469-

481/2016, publicado no periódico revista Engenharia Agrícola 36 (3):469-481, na página 179:

Onde se lia:

GEFFSON DE F. DANTAS ${ }^{1}$, ROGÉRIO T. DE FARIA ${ }^{2}$, GILMAR DE O. DOS SANTOS ${ }^{3}$, ALEXANDRE B. DALRI ${ }^{4}$, LUIZ F. PALARETTI ${ }^{5}$

Leia-se:

GEFFSON DE F. DANTAS ${ }^{1}$, ROGÉRIO T. DE FARIA ${ }^{2}$, GILMAR O. SANTOS ${ }^{3}$, ALEXANDRE B. DALRI ${ }^{4}$, LUIZ F. PALARETTI ${ }^{5}$ 